\title{
Effect of disaccharides on survival during storage of freeze dried probiotics
}

\author{
Song MiaO ${ }^{1}$, Susan Mills $^{1}$, Catherine StAnton $^{1,2 *}$, Gerald F. FitzGerald ${ }^{2,3}$, \\ Yrjo $\operatorname{RoOs}^{4}$, R. Paul Ross ${ }^{1,2}$ \\ ${ }^{1}$ Teagasc Moorepark Food Research Centre, Fermoy, County Cork, Ireland \\ ${ }^{2}$ Alimentary Pharmabiotic Centre, Biosciences Institute, County Cork, Ireland \\ ${ }^{3}$ Department of Microbiology, University College Cork, County Cork, Ireland \\ ${ }^{4}$ Department of Food and Nutritional Sciences, University College Cork, County Cork, Ireland
}

\begin{abstract}
The aim of this study was to investigate the effects of protective media and different relative vapour pressures (RVPs) on the survival of probiotics during freeze drying and subsequent storage, to determine the optimal conditions for the production of freeze dried probiotics at industrial scale, ensuring a high survival rate. The effect of protective media i.e. reconstituted skimmed milk (RSM) or either of the cryoprotective disaccharides lactose, trehalose, sucrose, maltose, lactose + maltose and lactose + trehalose on the survival of a probiotic culture was assessed at five different RVP environments $(0.0 \%, 11.4 \%, 33.2 \%, 44.1 \%$ and $76.1 \%)$ at room temperature in freeze-dried systems. RVP was shown to have a significant effect on the survival rates of the probiotic cultures Lactobacillus paracasei NFBC 338 and Lactobacillus rhamnosus GG following freeze drying in RSM. Interestingly, retention of cell viability was greatest for cells stored at $11.4 \%$ RVP, but was compromised at all other RVPs tested. However, an increased tolerance to freeze drying was observed for L. rhamnosus GG when dried in the presence of disaccharides in the order of trehalose $=$ lactose + maltose $\geqslant$ lactose + trehalose $\geqslant$ maltose $>$ lactose $>$ sucrose. Survival studies over a 38-40 day storage period indicated that trehalose and lactose + maltose were the most effective cryoprotective additives, especially notable at 0.0 and $11.4 \%$ RVP. At all other RVPs tested, viability was compromised. Crystallisation of the disaccharides was observed to be a detrimental factor affecting the survival of Lactobacillus during storage at high RVP, where an inverse relationship was shown to exist between the \% RVP and the glass transition temperature $\left(\mathrm{T}_{\mathrm{g}}\right)$ of the disaccharides.
\end{abstract}

probiotics / storage / viability / relative vapour pressure / disaccharides

摘要 - 二糖对益生菌的冻干保护作用。为了获得高活力益生菌冷冻干燥的最佳生产条 件, 实现工业化生产, 本文研究了保护介质和相对蒸汽压对益生菌冷冻干燥过程及咜藏过 程中活力的影响。保护介质采用还原乳 (RSM), 或冻干保护剂二糖: 乳糖、海澡糖、蔗 糖、麦芽糖、乳糖+麦芽糖和乳糖+海藻糖混合物, 在室温下, 研究了五种不同相对蒸汽压 $(0.0 \%, 11.4 \%, 33.2 \%, 44.1 \%$ 和 $76.1 \%)$ 对菌种冻干的影响。实验证明在还原乳培养基中, 不 同相对蒸汽压对具有益生作用的干酪乳杆菌 (Lactobacillus paracasei) NFBC338 和鼠李糖 乳杆菌 (Lactobacillus rhamnosus) LGG 的活力有显著的影响, 在 $11.4 \%$ 相对蒸汽压下, 细 胞存活率最大, 而其他的相对蒸汽压下细胞存活率较低。二糖对鼠李糖 LGG 冻干保护作 用的顺序为海藻糖 $=$ 乳糖 + 麦芽糖 $\geqslant$ 乳糖 + 海藻糖 $\geqslant$ 麦芽糖 $>$ 乳糖 $>$ 庶糖。通过 38-40

*Corresponding author (通讯作者): catherine.stanton@teagasc.ie 


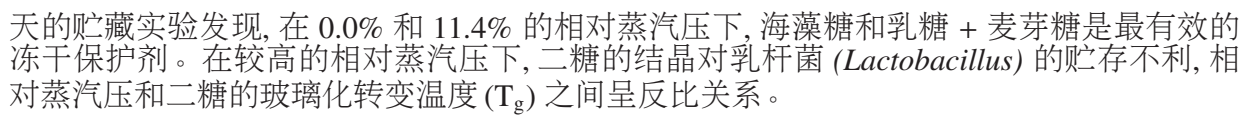
益生菌 / 保藏 / 活力 / 相对蒸汽压 / 二糖

Résumé - Effet des disaccharides sur la survie de probiotiques lyophilisés au cours du stockage. Le but de cette étude était de rechercher les effets de milieux protecteurs et de différentes pressions de vapeur relatives (PVR) sur la survie de probiotiques au cours de la lyophilisation et du stockage ultérieur, afin de déterminer les conditions optimales pour la production de probiotiques lyophilisés à l'échelle industrielle assurant un taux de survie élevé. L'effet de milieux de protection, i.e. lait écrémé reconstitué ou l'un des disaccharides cryoprotecteurs suivants : lactose, tréhalose, saccharose, maltose, lactose + maltose ou lactose + tréhalose, sur la survie d'une culture de probiotiques a été étudié dans 5 environnements de PVR différents $(0 ; 11,4 ; 33,2 ; 44,1$ et 76,1\%) à température ambiante dans des systèmes lyophilisés. On a montré que la PVR avait un effet significatif sur les taux de survie des cultures de probiotiques Lactobacillus paracasei NFBC 338 et Lactobacillus rhamnosus GG après lyophilisation dans le lait écrémé reconstitué : le maintien de la viabilité cellulaire était plus élevé pour des cellules conservées à une PVR de 11,4\%, alors qu'il était compromis à toutes les autres PVR étudiées. Cependant, une tolérance accrue à la lyophilisation était observée pour L. rhamnosus GG en présence de disaccharides, dans l'ordre tréhalose $=$ lactose + maltose $\geqslant$ lactose + tréhalose $\geqslant$ maltose $>$ lactose $>$ saccharose. Les études de survie sur 38-40 jours ont mis en évidence que le tréhalose et le lactose + maltose étaient les additifs cryoprotecteurs les plus efficaces, surtout à 0 et 11,4\% de PVR. À toutes les autres PVR testées, la viabilité était compromise. On a observé que la cristallisation des disaccharides était préjudiciable à la survie de Lactobacillus au cours du stockage aux PVR élevées, une relation inverse ayant été montrée entre le \% de PVR et la température de transition vitreuse $\left(\mathrm{T}_{\mathrm{g}}\right)$ des disaccharides.

\section{probiotiques / stockage / survie / pression de vapeur relative / disaccharides}

\section{INTRODUCTION}

Scientific evidence on the health benefits associated with the consumption of probiotic bacteria continues to accumulate at a rapid rate. As both consumer and medical interest in the use of probiotics as prophylactic and therapeutic treatments increases, a vast need to adapt these microorganisms for industrial-scale production has arisen. It has been suggested that up to $10^{6}$ colony forming units $(\mathrm{cfu}) \cdot \mathrm{g}^{-1}$ of probiotic bacteria should be present in a fermented food product at the end of its shelf-life [7]. Thus, the development of concentrated viable starter cultures is required to successfully incorporate these microorganisms into food products at the required numbers. For this reason, the generation of live cultures in powder format is an attractive option. Indeed, both freeze drying and spray drying can be used for the manufacture of probiotic powders on a large scale. However, in both processes the cultures are exposed to extremely harsh environmental conditions, such as dehydration, compromising both the viability and functionality of the dried probiotic culture. Thus, major efforts have been invested in modifying the drying process to eliminate cellular damage and increase viability of the dried product.

Freeze drying is especially appealing as it results in the production of a powder with a high specific surface area and therefore a fast re-hydration rate $[20,26,33]$. Initially the product is frozen to below the critical temperature of the formulation, at which maximum water is frozen. This is followed by a primary drying step, where unbound water is removed by sublimation, and finally a secondary drying stage where bound water is removed by desorption [26, 33]. Freeze drying has some undesirable 
effects, resulting in a change in the physical state of membrane lipids and a change in the structure of sensitive proteins [29]. However, the presence of a suitable cryoprotective additive usually increases the survival considerably [25].

Interestingly, in nature many plants and animals have the ability to survive almost complete dehydration, a phenomenon known as anhydrobiosis [35]. Accumulation of disaccharides, especially sucrose and trehalose appears to be a common feature in such organisms [24, 27, 34]. Major research efforts have thus focused on the use of these and other disaccharides as additives to promote dessication tolerance during the drying process $[4,8,29,36,40]$. Addition of a disaccharide to the cells before drying serves a multiple role by replacing hydrogen bonds lost upon drying and by forming a glass structure with high viscosity and low motility, thus restricting molecular interactions, hence the substance is in a frozen state $[11,12,14,35]$. In addition, water has a significant effect on the glass transition temperature $\left(\mathrm{T}_{\mathrm{g}}\right)$. The $T_{g}$ value of a given hydrophilic substance is decreased as the water content is increased, following a non-linear function [5]. However, if the water content is further increased, the solid material loses viscosity and collapses or crystallises [35].

This study examined the effect of the storage relative vapour pressure (RVP) upon survival of two stationary phase, freeze dried probiotic strains, namely Lactobacillus paracasei NFBC 338 and Lactobacillus rhamnosus GG at five different RVP environments $(0.0 \%, 11.4 \%$, $33.2 \%, 44.1 \%$ and $76.1 \%$ ) at room temperature. The effect of protective media at the above RVPs on the survival of L. rhamnosus GG was then assessed and the relationship between $\mathrm{T}_{\mathrm{g}}$ of the cryoprotective media and cell survival was demonstrated. Previous research in our laboratory indicated that the human derived L. paracasei NFBC 338 was a suitable candidate for spray-drying [19]. In addition, attempts to improve its dessication tolerance proved successful through heat and salt adaptation prior to drying [17] and through overexpression of the GroESL chaperone protein [16] which was also shown to enhance its survival under the stressful conditions of drying [9]. The human derived L. rhamnosus GG is a commercial probiotic strain with recognised health benefits [31, 32] and has been exploited for use in the development of functional foods $[1,18]$. Ananta and Knorr [2] previously demonstrated that pressure adaptation improved the survival of $L$. rhamnosus GG during spray drying at an outlet temperature of $80^{\circ} \mathrm{C}$. In addition, it was also established that stationary phase cultures of $L$. rhamnosus GG were more suitable for drying processes [10]. It was important therefore, to examine parameters which could potentially improve survival of both of these strains after the freeze drying process.

\section{MATERIALS AND METHODS}

\subsection{Bacterial strains and culture conditions}

The probiotic strains L. paracasei ssp. paracasei NFBC 338 and L. rhamnosus GG were obtained from University College Cork, under a restricted materials transfer agreement. Harvested cells of these strains were stored as stock solutions in $40 \%$ (v/v) aqueous glycerol at $-80{ }^{\circ} \mathrm{C}$. They were subcultured at $1 \%(\mathrm{v} / \mathrm{v})$ in MRS Oxoid broth (Oxoid Ltd, Hampshire, UK) for $\sim 17 \mathrm{~h}$ at $37{ }^{\circ} \mathrm{C}$ under anaerobic conditions, obtained by placing one activated Anaerocult A gas pack (Merck, Darmstedt, Germany) in a jar, which was subsequently sealed. 


\subsection{Preparation of stationary phase cultures for freeze drying}

Following growth of a $1 \%$ inoculum in MRS broth or $15 \%$ RSM (reconstituted skimmed milk; Golden Vale, Cork, Ireland), early stationary phase cells were harvested under aseptic conditions by centrifugation $\left(15 \mathrm{~min}\right.$ at $9722 \times g$ at $4{ }^{\circ} \mathrm{C}$ ) and re-suspended in the equivalent volume of the desired protective medium. Cell viability was determined immediately after suspension by pour plating the appropriate serial dilutions on MRS agar and enumerating after $24 \mathrm{~h}$ of incubation under anaerobic conditions. All experiments with cultures were performed in triplicate.

\subsection{Freeze drying and storage in the presence of disaccharides at 5 different RVPs}

The following media was used to protect cells during the freezing and freeze drying process; RSM $(15 \% \mathrm{w} / \mathrm{v})$, or either lactose, trehalose, sucrose, maltose (Sigma-Aldrich, Dublin, Ireland), lactose/trehalose (1:1 mix), lactose/maltose $(1: 1 \mathrm{mix})$ at $15 \%(\mathrm{w} / \mathrm{v})$ concentration of solids in the presence of distilled water. Distilled water was also used as a control medium for comparison. Prior to freezing or freeze drying, the cells were resuspended in the appropriate protective media as previously described. Suspensions (2.5 mL aliquots) were then transferred into $10 \mathrm{~mL}$ glass vials under aseptic conditions, frozen with open stoppers for $21 \mathrm{~h}$ at $-80{ }^{\circ} \mathrm{C}$ and freeze dried in vials for $48 \mathrm{~h}$ ( $\mathrm{P}<0.1$ mbar). For freeze drying, the open glass vials with stoppers were placed on trays inside the freeze-drier and stoppers were closed before the vacuum was released from the drying chamber at the end of the drying process. After freezing and before freeze drying, the cell viability of frozen suspensions was determined.
Freeze dried materials in the glass vials were stored in vacuum desiccators, with stoppers opened, at five RVP values using four saturated salt solutions, where $\mathrm{P}_{2} 0_{5}$ was used to maintain $0.0 \%$ RVP, (11.4\%: $\mathrm{LiCl} ; 33.2 \%: \mathrm{MgCl}_{2} ; 44.1 \%$ : $\mathrm{K}_{2} \mathrm{CO}_{3} ; 76.1 \%: \mathrm{NaCl}$ ) [22,28] which were confirmed by a water activity meter (Aqua Lab, CX-2, Decagon Devices, Inc. Pullman, Washington, USA). The solutions were autoclaved at $121^{\circ} \mathrm{C}$ for $15 \mathrm{~min}$. The desiccators were stored at $22-25{ }^{\circ} \mathrm{C}$. For the enumeration of microorganisms in the freeze dried powders, the powders were resuscitated in maximum recovery diluents (MRD; $10 \% \mathrm{w} / \mathrm{v}$; Oxoid) for $1 \mathrm{~h}$ at $37{ }^{\circ} \mathrm{C}$ and the appropriate serial dilutions were prepared prior to pour plating on MRS agar in independent triplicate experiments. Triplicate samples were removed at 0,2, 4, 11,25 and 38 days and an equivalent volume of sterilized maximum recovery diluent (MRD; $10 \% \mathrm{w} / \mathrm{v}$; Oxoid) was added to recover the dried suspension to the same concentration as it was. Cell viability was determined as cfu $\cdot \mathrm{mL}^{-1}$ after $24 \mathrm{~h}$ of incubation under anaerobic conditions. A 1way ANOVA followed by multiple range (LSD) tests were performed using SPSS 11.0 (SPSS Inc., Chicago, IL, USA) to compare cell viability affected by the different protective media and different RVPs. The level of confidence required for significance was selected as $P \leqslant 0.05$.

\subsection{Measurement of glass transition temperature}

Differential scanning calorimetry (DSC, Mettler Toledo 821e, Schwerzenbach, Switzerland) was used to measure $T_{g}$ for dehydrated and rehumidified samples as described by Lievonen et al. [30]. Freeze-dried samples (9 to $15 \mathrm{mg}$ ) were prepared in pre-weighed DSC aluminum pans $(40 \mu \mathrm{L}$; Mettler Toledo-27331, Schwerzenbach, Switzerland) and stored 
in open pans for $144 \mathrm{~h}$ at $22-25^{\circ} \mathrm{C}$ in evacuated desiccators over $\mathrm{P}_{2} \mathrm{O}_{5}$ and different saturated salt solutions, as described previously, giving a water activity, $\mathrm{a}_{\mathrm{w}}$, of $0.01 \times \mathrm{RVP}$ at equilibrium [27]. RVP of the saturated salt solutions were confirmed with an AquaLab CX-2 water activity meter. After equilibration, the pans were hermetically sealed. Triplicate samples of each material were analyzed. An empty pan was used as a reference. The DSC was calibrated for temperature and heat flow using indium (melting point, $156.6{ }^{\circ} \mathrm{C}$, $\Delta \mathrm{Hm}, 28.5 \mathrm{~J} \cdot \mathrm{g}^{-1}$ ), n-pentane (melting point, $\left.-129.7{ }^{\circ} \mathrm{C}, \Delta \mathrm{Hm}, 116.7 \mathrm{~J} \cdot \mathrm{g}^{-1}\right)$, n-hexane (melting point, $-94.0^{\circ} \mathrm{C}, \Delta \mathrm{Hm}$, $151.8 \mathrm{~J}^{-\mathrm{g}^{-1}}$ ), distilled water (melting point, $0{ }^{\circ} \mathrm{C}, \Delta \mathrm{Hm}, 334.5 \mathrm{~J} \cdot \mathrm{g}^{-1}$ ), and gallium (melting point, $28.9^{\circ} \mathrm{C}, \Delta \mathrm{Hm}, 80.0 \mathrm{~J} \cdot \mathrm{g}^{-1}$ ). The samples were scanned first over the glass transition range at $5{ }^{\circ} \mathrm{C} \cdot \mathrm{min}^{-1}$, then cooled at $10{ }^{\circ} \mathrm{C} \cdot \mathrm{min}^{-1}$ to at least $30{ }^{\circ} \mathrm{C}$ below the glass transition, and a second heating scan at $5{ }^{\circ} \mathrm{C} \cdot \mathrm{min}^{-1}$ was run to at least $30{ }^{\circ} \mathrm{C}$ above the glass transition. Samples with various water contents were scanned in hermetically sealed pans. Glass transitions were analyzed using STARe thermal analysis software, version 6.0 (Mettler Toledo). The $\mathrm{T}_{\mathrm{g}}$ was taken from the onset temperature of the $\mathrm{T}_{\mathrm{g}}$ range. An average obtained for three replicate samples was taken as the $\mathrm{T}_{\mathrm{g}}$.

\section{RESULTS}

\subsection{Effect of storage RVP on survival of freeze dried probiotic strains grown in reconstituted skimmed milk (RSM)}

The survival of freeze dried cultures of L. paracasei NFBC 338 and L. rhamnosus GG in $15 \%$ RSM media was assessed over a 38 day period at different RVPs (Figs. 1a and $1 \mathrm{~b}$ ). The most dramatic loss in cell viability occurred for cells stored at the RVP of $76.1 \%$. Most interestingly however, the highest viability was observed for both cultures stored at $11.4 \%$ RVP. In this case, the number of cells for L. paracasei NFBC 338 decreased from $2.8 \times 10^{9} \pm 0.0 \mathrm{cfu} \cdot \mathrm{mL}^{-1}$ at day 0 to $6.3 \times 10^{8} \pm 0.3 \mathrm{cfu} \cdot \mathrm{mL}^{-1}$ at day 38 , resulting in a $22.0 \%$ survival rate. The percent survival was even more dramatic for L. rhamnosus GG where the number of cells decreased from only $1.4 \times 10^{9} \pm 0.0$ to $9.4 \times 10^{8} \pm 0.1 \mathrm{cfu} \cdot \mathrm{mL}^{-1}$ over the same period, resulting in a $65.4 \%$ survival rate. In the case of both cultures, storage RVPs of $33.2 \%$ and $0.0 \%$ appeared to have a similar effect on cell viability (Fig. 1) where cell counts were reduced by approximately 2 logs over the 38 day storage period. The decrease in viability was also dramatic for cells stored at $44.1 \%$ RVP, where a survival rate of approximately $0.02 \%$ was observed for both strains over the 38 days.

\subsection{Freezing and freeze drying of L. rhamnosus GG in different disaccharides}

Previous studies have indicated that disaccharides exert a protective effect in cryomicrobiology [25]. Table I shows the percent survival rates of $L$. rhamnosus GG following freezing and freeze drying in the different freeze drying media. As can be seen from the control (cells alone), both freezing and freeze drying resulted in loss of cell viability. Indeed, in the absence of a cryoprotective additive, cell viability was reduced by $3.7 \%$ (96.3\% survival) after freezing and by $12.1 \%$ (87.9\% survival) after freeze drying. Overall, the addition of disaccharides to the cells did contribute to the survival of L. rhamnosus after freeze drying in the order of trehalose $\geqslant$ maltose $>$ lactose $>$ sucrose. Interestingly, the disaccharide mixes lactose + maltose and lactose + trehalose resulted in $98.7 \%$ and $97.5 \%$ survival, respectively, affording the cells approximately the same level of 
(a)

L. rhamnosus GG

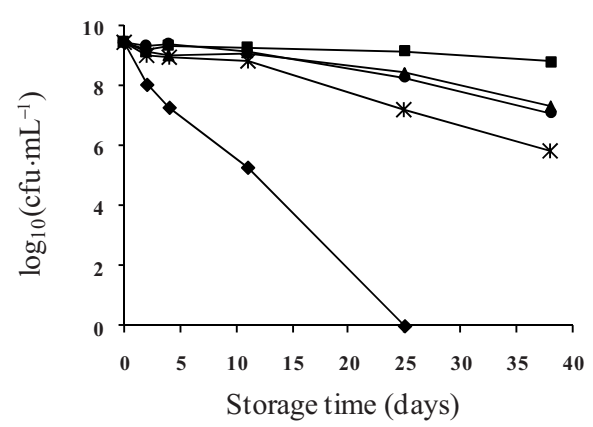

(b)

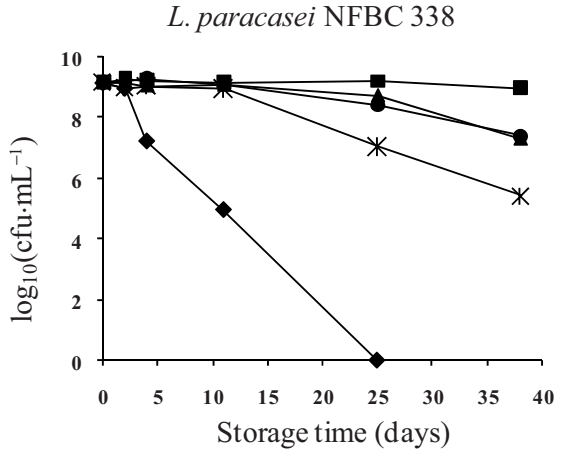

Figure 1. Retention of cell viability of freeze dried Lactobacillus rhamnosus GG (a) and Lactobacillus paracasei NFBC 338 (b) in RSM at $0.0(\bullet), 11.4(\bullet), 33.2(\mathbf{\Delta}), 44.1(*)$ and $76.1 \%$ ( ) RVP over a 38 day storage period.

protection as trehalose itself. However, the order of most effective cryoprotectant differed for the frozen cultures as follows, trehalose $>$ sucrose $>$ maltose $>$ lactose. Indeed, compared to the control (cells alone), maltose and lactose afforded no protection to the frozen cells. On the other hand, the disaccharide mixes were most effective at protecting cells, with survival rates in the region of 99 and $100 \%$.

\subsection{Effect of storage RVP on survival of freeze dried L. rhamnosus GG in the presence of disaccharides}

While the presence of disaccharides contributed to the survival of cells directly after freeze drying, it was necessary to determine the effect of storage RVP on cell viability following freeze drying with the above disaccharides. Figure $2 \mathrm{a}$ shows viability of L. rhamnosus after freeze drying in the presence of trehalose over a 38-40 day storage period at the RVPs previously tested. Initial cell numbers were recorded at $2.2 \times 10^{9} \pm 0.1 \mathrm{cfu} \cdot \mathrm{mL}^{-1}$ on day 0 . Highest survival was obtained at $0.0 \% \operatorname{RVP}\left(2.7 \times 10^{9} \pm 0.0 \mathrm{cfu} \cdot \mathrm{mL}^{-1}\right)$ followed by $11.4 \% \operatorname{RVP}\left(2.1 \times 10^{9} \pm\right.$
$0.0 \mathrm{cfu} \cdot \mathrm{mL}^{-1}$ ) and lowest at $76.1 \% \mathrm{RVP}$ over the 38 day period. Indeed, at $76.1 \%$ RVP loss in cell viability was observed after 18 days of storage. Cell viability was also dramatically reduced at storage RVPs of 33.2 and $44.1 \%$ over the 38 day period. A similar pattern was observed for the disaccharides lactose, maltose and sucrose, where RVPs of 0.0 and $11.4 \%$ resulted in highest survival (Figs. 2b, 2c and 2d). Interestingly, at $0.0 \% \mathrm{RVP}$, sucrose was more effective at retaining cell viability than maltose, resulting in $55.0 \%$ and $43.4 \%$ survival, respectively, at the end of the storage period. However, at $11.4 \%$ RVP, survival in the presence of sucrose was reduced to $10.0 \%$, as opposed to $54.1 \%$ for maltose (Fig. 2c). Overall, trehalose was the most effective cryoprotectant at RVPs of 0.0 and $11.4 \%$, resulting in $100.0 \%$ and $95.5 \%$ viability after 38 days of storage, respectively. This was closely followed by lactose which resulted in survival rates of $100.0 \%$ and $86.2 \%$ at RVPs of 0.0 and $11.4 \%$, respectively. Thus the order of most effective cryoprotective additive at $0.0 \%$ RVP was as follows, trehalose $>$ lactose $>$ sucrose $>$ maltose. However, at $11.4 \%$ RVP, the order changed to trehalose $>$ lactose $>$ maltose $>$ sucrose. 
Table I. Percent survival of Lactobacillus rhamnosus GG following freezing and freeze drying in $15 \%$ disaccharides.

\begin{tabular}{|c|c|c|c|c|c|c|c|}
\hline & Control $^{\theta}$ & Lactose & Trehalose & Maltose & Sucrose & $\mathbf{L} / \mathbf{T}^{\S}$ & $\mathbf{L} / \mathbf{M}^{\S}$ \\
\hline Before freezing & $100.0 \pm 0.1$ & $100.0 \pm 0.7$ & $100.0 \pm 0.9$ & $100.0 \pm 0.7$ & $100.0 \pm 0.3$ & $100.0 \pm 0.5$ & $100.0 \pm 1.2$ \\
\hline After freezing & $96.3 \pm 0.0 *$ & $94.8 \pm 0.1^{*}$ & $99.8 \pm 1.0^{* *}$ & $96.2 \pm 0.0 *$ & $97.6 \pm 0.7 * *$ & $* 100.0 \pm 0.1 * *$ & $99.0 \pm 0.3^{* *}$ \\
\hline $\begin{array}{l}\text { After freeze } \\
\text { drying }\end{array}$ & $87.9 \pm 0.1^{*}$ & $93.7 \pm 0.0 * *$ & $97.1 \pm 0.1 * *$ & $96.4 \pm 0.3^{* *}$ & $88.4 \pm 0.2^{*}$ & $97.5 \pm 0.3^{* *}$ & $98.7 \pm 1.1 * *$ \\
\hline
\end{tabular}

Control $^{\theta}$ : no protective media; ${ }^{\S} \mathrm{L} / \mathrm{T}$ : Lactose/Trehalose; L/M: Lactose/Maltose.

* Significant; ** not significant $(P \leqslant 0.05)$. All experiments with cultures were performed in triplicate.

Note: Mean values from 'before freezing' were compared with mean values from 'after freezing'; mean values from 'after freeze drying' were compared with mean values from 'after freezing'.

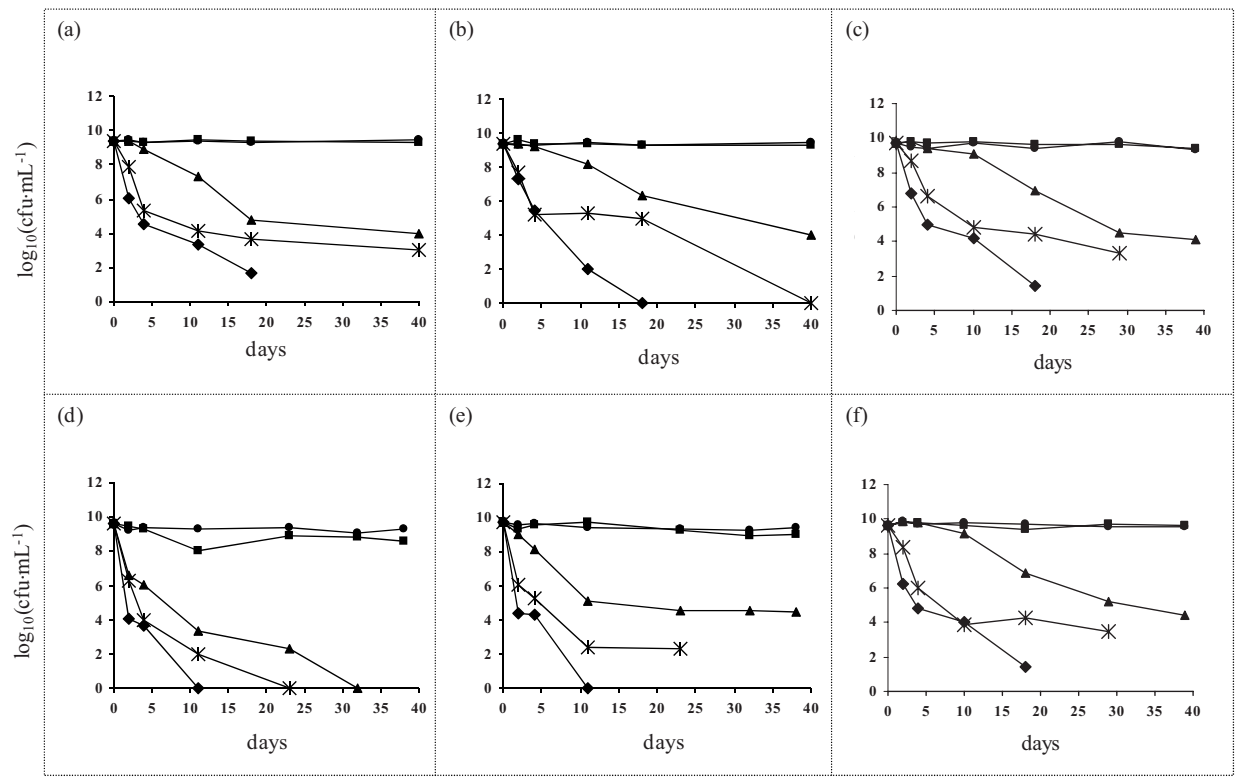

Figure 2. Retention of cell viability of freeze dried Lactobacillus rhamnosus GG in the presence of trehalose (a), lactose (b), maltose (c), sucrose (d), lactose + trehalose (e) and lactose + maltose (f)

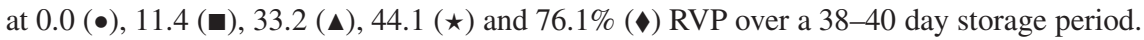

Studies were then performed using mixes of the most effective cryoprotectants, trehalose, lactose and maltose over the 38 day storage period at the above RVPs. There was no significant loss in the viability of the cells when freeze dried in the presence of lactose + maltose or lactose + trehalose at $0.0 \%$ RVP (Figs. 2e and $2 \mathrm{f})$. In the case of lactose + trehalose, the cell number dropped from $5.9 \times 10^{9} \pm$
$0.1 \mathrm{cfu} \cdot \mathrm{mL}^{-1}$ to $2.5 \times 10^{9} \pm 0.1 \mathrm{cfu} \cdot \mathrm{mL}^{-1}$ giving a survival rate of $42.7 \%$ at $0.0 \%$ RVP over the 38 day storage period. The lactose + maltose mix was superior however at the same RVP, in this case the cell number dropped from $4.4 \times 10^{9} \pm 0.2$ to $3.8 \times 10^{9} \pm 0.1 \mathrm{cfu} \cdot \mathrm{mL}^{-1}$ over the same time period, resulting in $86.4 \%$ survival. Interestingly, viability at $11.4 \%$ RVP in the presence of lactose + maltose was far 
superior again, resulting in $100.0 \%$ survival as compared with $18.0 \%$ for lactose + trehalose. Overall, lactose + maltose was the most effective disaccharide mix when cells were stored at RVPs of 0.0 and $11.4 \%$.

\subsection{Glass transition temperatures of the model systems at various RVPs and effect of glass transition temperature on cell viability}

Glass transition temperatures (onset temperature of glass transition) determined for the disaccharides and the disaccharide mixes at the RVPs used in this study are listed in Table II. Most notably the $\mathrm{T}_{\mathrm{g}}$-values of the disaccharides decreased with increasing water content. Indeed, it has previously been demonstrated that the $\mathrm{T}_{\mathrm{g}}$ of carbohydrates is very sensitive to water [36] which is an effective plasticizer of amorphous materials. An increase in the water content of the dried matrix results in a simultaneous decrease in viscosity resulting in physical changes such as collapse, crystallization, and stickiness. At $44.1 \%$ RVP, RSM, lactose and trehalose were found to crystallize. However, sucrose was the most sensitive, crystallizing at $33.2 \% \mathrm{RVP}$ and indeed displayed the lowest value for $\mathrm{T}_{\mathrm{g}}\left(51{ }^{\circ} \mathrm{C}\right.$ at $\left.0.0 \% \mathrm{RVP}\right)$. Interestingly, the $\mathrm{T}_{\mathrm{g}}$ values for lactose, trehalose and the lactose/trehalose mix were similar for samples stored at 0.0\% RVP, with temperature values of 106.2, 107.9 and $107.3{ }^{\circ} \mathrm{C}$, respectively. Indeed, these three samples displayed similar $\mathrm{T}_{\mathrm{g}}$-values to each other at RVPs of $11.4,23.0$ and $33.2 \%$, although the values decreased with increasing RVP.

The difference between $T_{g}$ and the storage temperature $\mathrm{T},\left(\mathrm{T}-\mathrm{T}_{\mathrm{g}}\right)$, appears to control the rate of physical, chemical and biological changes of food systems [35]. The effect of $\mathrm{T}-\mathrm{T}_{\mathrm{g}}$ for both lactose and trehalose on the viability of L. rhamnosus GG was assessed after 40 days of storage (Fig. 3) at RVPs of 0.0, 11.4, 23.0 and $33.2 \%$. Highest cell viabilities were obtained when trehalose and lactose were used to protect cells at $0.0 \%$ RVP, where the $\mathrm{T}_{\mathrm{g}}$-values were calculated at 107.9 and $106.2^{\circ} \mathrm{C}$, respectively. Interestingly, at $\mathrm{T}_{\mathrm{g}}$-values of $53.8^{\circ} \mathrm{C}$ and $55.7^{\circ} \mathrm{C}$ for trehalose and lactose, respectively, cell viability was almost the same as cell viability at $0.0 \%$ RVP. However, as the $\mathrm{T}_{\mathrm{g}}$-values decreased after this point, cell viability also decreased. Interestingly, this decrease in cell viability was most dramatic at $\mathrm{T}_{\mathrm{g}}$ values below $53.8{ }^{\circ} \mathrm{C}$ and $55.7{ }^{\circ} \mathrm{C}$ for trehalose and lactose, respectively. It is worth noting that although viability of L. rhamnosus GG was in the region of $0.0 \mathrm{cfu} \cdot \mathrm{mL}^{-1}$ at $33.2 \% \mathrm{RVP}$ in the presence of either lactose or trehalose, viability was recorded at approximately $10^{4} \mathrm{cfu} \cdot \mathrm{mL}^{-1}$ under similar conditions in Figure 2 (a and b). The fact that both experiments were performed separately in different research centers accounts for such deviation, presumably due to slight variations of experimental parameters. However, the overall results concur, demonstrating that at RVP values above $11.4 \%$, considerable loss in cell viability can be expected.

\section{DISCUSSION}

The successful exploitation of probiotic bacteria for functional food products depends on the ability to produce concentrated preparations of the probiotic culture that can withstand the harsh conditions encountered during food processing, and remain viable for the shelf life of the product. As mentioned previously live cultures in powder format are an attractive option, however, sustaining viability during storage can be challenging. The use of a silica gel-carrier salt admixture has previously been deemed effective in 
Table II. Glass transition temperatures of the model systems at various relative vapour pressures in RSM (reconstituted skimmed milk) and in different disaccharides.

\begin{tabular}{ccrrrrrc}
\hline RVP (\%) & RSM & Lactose & Trehalose & Maltose & Sucrose & \multicolumn{1}{c}{ L/T } & \multicolumn{1}{c}{ L/M } \\
\hline 0.0 & $98.1 \pm 1.0$ & $106.2 \pm 0.4$ & $107.9 \pm 1.1$ & $90.6 \pm 0.7$ & $51.2 \pm 0.3$ & $107.3 \pm 0.5$ & $96.9 \pm 1.2$ \\
11.4 & $58.2 \pm 0.5$ & $55.7 \pm 1.0$ & $53.8 \pm 1.0$ & $46.0 \pm 1.3$ & $31.6 \pm 0.7$ & $53.6 \pm 1.2$ & $51.3 \pm 0.3$ \\
23.0 & $34.2 \pm 1.3$ & $40.4 \pm 0.2$ & $40.4 \pm 0.1$ & $31.7 \pm 0.9$ & $21.6 \pm 0.2$ & $40.1 \pm 0.3$ & $33.0 \pm 1.1$ \\
33.2 & $20.1 \pm 0.3$ & $30.4 \pm 0.4$ & $29.5 \pm 0.9$ & $23.0 \pm 0.1$ & $\mathrm{C}$ & $30.1 \pm 0.2$ & $25.9 \pm 0.4$ \\
44.1 & $* \mathrm{C}$ & $\mathrm{C}$ & $\mathrm{C}$ & $8.2 \pm 0.4$ & $\mathrm{C}$ & $11.8 \pm 0.2$ & $10.0 \pm 0.6$ \\
\hline
\end{tabular}

${ }^{\S} \mathrm{L} / \mathrm{T}$ : Lactose/Trehalose; L/M: Lactose/Maltose; ${ }^{*} \mathrm{C}$ : system crytallised.

Values highlighted in grey: below room temperature. All experiments were performed in triplicate.

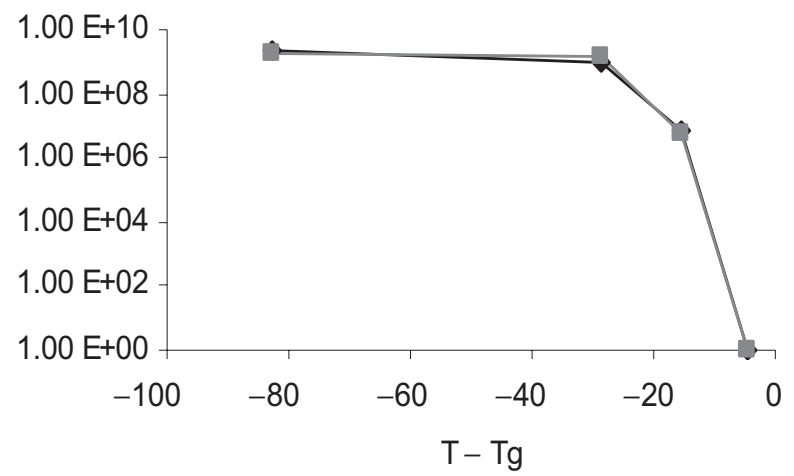

Figure 3. Effect of glass transition on the viability of Lactobacillus rhamnosus GG after 40 days of storage following freeze drying in the presence of trehalose $(\downarrow)$ or lactose $(\boldsymbol{\square})$.

maintaining viability of dried lactic acid bacterial cells [38]. The method of freeze drying is deemed particularly suitable for producing powders of biological materials as drying takes place at low temperatures, reducing chemical reaction rates and heat degradation [20,23]. This study examined the role of the disaccharides trehalose, lactose, maltose, lactose + trehalose and lactose + maltose as potential cryoprotective additives during the freeze drying process and subsequent storage of the probiotic strain, L. rhamnosus GG. In particular, the effect of RVP and glass transition of the disaccharides on cell viability over the storage period was assessed.

Previous results have indicated that RSM is a relatively effective freeze drying medium [25]. Remarkably, our results showed that it was most beneficial when the cells were stored at $11.4 \%$ RVP, with survival rates of $22.0 \%$ and $65.4 \%$ for L. paracasei NFBC 338 and L. rhamnosus, respectively. However, at all other RVPs tested, viability was compromised.

As previously mentioned, the accumulation of certain disaccharides has enabled both plants and animals to survive almost complete dehydration. One of the main aspects of freeze drying is the removal of both unbound and bound (hydrogen-bonded) water. It is now known that the addition of disaccharides compensate for water loss by replacing the hydrogen bonds through interactions with the polar headgroups of the cell membrane and cellular proteins $[3,11]$, preventing changes in their physical state and structures. Indeed, several studies have reported the positive effect of adding disaccharides 
to the drying media $[4,29,37]$. The disaccharides under investigation in this study enhanced the retention of cell viability of L. rhamnosus GG during freeze drying. Interestingly, the order of most effective cryoprotectant differed between samples that had been frozen and those which had been freeze dried, although trehalose was the most effective additive in both processes. Most notably, sucrose was least effective in retaining cell viability for freeze dried samples, yet came second to trehalose for retaining viability in frozen samples. It has previously been reported that $5 \%$ sucrose protected concentrated starter strains of Lactococcus lactis ssp. lactis better than $10 \%$ glycerol when stored at -20 to $-70{ }^{\circ} \mathrm{C}[6]$. However, it has also been reported that three times more sucrose $\left(\mathrm{g} \cdot \mathrm{g}^{-1}\right.$ of cell membrane) is required to exert the same effect as trehalose during freeze drying [13]. Interestingly, trehalose was as effective a cryoprotectant as the mixes of lactose + trehalose and lactose + maltose.

Subsequent survival studies of L. rhamnosus in the presence of the disaccharides at different RVPs indicated that trehalose was the most effective cryoprotectant at all RVPs tested. However, surprisingly, the lactose + maltose mix was more effective than lactose + trehalose. Indeed, lactose + maltose provided the same level of protection as trehalose itself. The effectiveness of trehalose is hardly surprising, considering that it is a natural cryoprotectant present in both plant and yeast cells [25]. Indeed, several studies have highlighted the effectiveness of trehalose in promoting dessication tolerance $[11,15,21,29,35]$. It is therefore inviting to assume, that rather than exert an additive effect on the cryoprotective capabilities of trehalose, lactose compromised them.

The success of disaccharides as cryoprotective additives owes in part to their ability to form glasses (vitrification), which have very high viscosity and low mobility, leading to the increased viability of the preserved material [35]. For example, according to Patist and Zoerb [35] a strong correlation exists between the $T_{g}$ of food products and their viability/shelflife. Below the $T_{g}$, food systems tend to be stable; above this temperature the difference between the $T_{g}$ and the storage temperature $\mathrm{T},\left(\mathrm{T}-\mathrm{T}_{\mathrm{g}}\right)$, appears to control the rate of physical, chemical and biological changes [34]. When samples are stored at temperatures above the $\mathrm{T}_{\mathrm{g}}$, free volume and total volume of samples increase, providing sufficient room for molecular motions [39], thus denaturation can occur. Likewise, $\mathrm{T}_{\mathrm{g}}$ has a similar effect on cell viability. As observed from our studies, the disaccharides with highest $\mathrm{T}_{\mathrm{g}}$-values (trehalose, lactose and maltose) were most effective in retaining cell viability over the storage period. However, water has a significant effect on $\mathrm{T}_{\mathrm{g}}$. It has been demonstrated that the $\mathrm{T}_{\mathrm{g}}$-value of a given hydrophilic substance decreases with an increase in water content, following a non-linear function as described by the Gordon-Taylor equation [5], a phenomenon also observed for the disaccharides analysed in this study. Indeed, as the water content is further increased, viscosity is reduced to a point where collapse or crystallisation of the solid material occurs as observed for RSM, lactose and trehalose at $44.1 \%$ RVP, while sucrose crystallised at $33.2 \%$ RVP.

In essence, disaccharides function best at lower RVPs due to the higher $\mathrm{T}_{\mathrm{g}}$ 's. Sucrose had the lowest $\mathrm{T}_{\mathrm{g}}$ at all the RVPs tested, explaining the inability of sucrose to provide the same level of protection as the other disaccharides. However, the $\mathrm{T}_{\mathrm{g}}$-values of trehalose, lactose, and lactose + trehalose were within similar ranges yet trehalose was the most effective cryoprotective additive. Considering that trehalose, maltose and sucrose are chemical isomers of each other with the chemical formula $\mathrm{C}_{12} \mathrm{H}_{22} \mathrm{O}_{11}$, it is remarkable that 
trehalose has a greater ability to stabilise the cells. This phenomenon can be attributed to its higher effectiveness as a hydrogen bond donor, as compared to other disaccharides [35]. In addition, trehalose has been reported to have more flexibility within its 2 monomers, compared to sucrose and maltose [13] allowing trehalose to conform with the irregular polar groups of macromolecules thus providing better interactions. Moreover, trehalose has also been reported to have a superior ability as a water structure breaker molecule [35]. By disrupting the tetrahedral hydrogen bond network of water, trehalose reduces the amount of freeze-able water available.

In conclusion, disaccharides with higher $\mathrm{T}_{\mathrm{g}}$ 's are generally more stable, therefore restricting biomolecules and molecular interactions, preventing denaturation of biological materials. This was directly reflected in Figure 3, where cell viability decreased as the $\mathrm{T}_{\mathrm{g}}$ decreased, representing a parallel relationship. On the other hand, an inverse relationship exists between the $\mathrm{T}_{\mathrm{g}}$ of a substance and the \% RVP, with higher RVPs resulting in reduced $\mathrm{T}_{\mathrm{g}}$-values and potential crystallisation. The ideal cryoprotective additive for stabilisation of probiotic microorganisms in a food product must maintain a high $\mathrm{T}_{\mathrm{g}}$ at humidity values recorded under normal storage conditions $\left(22-25{ }^{\circ} \mathrm{C}\right)$. We conclude that the disaccharides, trehalose, lactose, and lactose + maltose can provide a sufficient level of protection, ensuring minimum loss in cell viability especially at RVP values of 0.0 and $11.4 \%$. However, under normal storage conditions these disaccharides should also be effective cryoprotectants as their $\mathrm{T}_{\mathrm{g}}$-values are well above normal room temperature.

\section{REFERENCES}

[1] Ahola A.J., Yli-Knuuttila H., Suomalainen T., Poussa T., Ahlstrom A., Meurman J.H., Korpela R., Short-term consumption of probiotic-containing cheese and its effects on dental caries risk factors, Arch. Oral Biol. 47 (2002) 799-804.

[2] Ananta E., Knorr D., Evidence on the role of protein biosynthesis in the induction of heat tolerance of Lactobacillus rhamnosus GG by pressure pre-treatment, Int. J. Food Microbiol. 96 (2004) 307-313.

[3] Carpenter J.F., Crowe J.H., Modes of stabilization of a protein by organic solutes during dessication, Cryobiology 25 (1989) 459470.

[4] Carvalho A.S., Silva J., Ho P., Teixeira P., Malcata F.X., Gibbs P., Effects of various sugars added to growth and drying media upon thermotolerance and survival throughout storage of freeze-dried Lactobacillus delbreuckii ssp. bulgaricus, Biotechnol. Prog. 20 (2004) 248-254.

[5] Champion D., Le Meste M., Simatos D., Towards an improved understanding of glass transition and relaxations in foods: molecular mobility in the glass transition range. Trends Food Sci. Technol. 11 (2000) 41-55.

[6] Chavarri F.J., De Paz M., Nuǒez M., Cryoprotective agents for frozen concentrated starters from non-bitter Streptococcus lactis strains, Biotechnol. Lett. 10 (1988) 11-16.

[7] Codex standard for fermented milks, Codex Stan 243-2003.

[8] Conrad P.B., Miller D.P., Cielenski P.R., de Pablo J.J., Stabilisation and preservation of Lactobacillus acidophilus in saccharide matrices, Cryobiology 41 (2000) 17-24.

[9] Corcoran B.M., Ross R.P., Fitzgerald G.F., Dockery P., Stanton C., Enhanced survival of GroESL-overproducing Lactobacillus paracasei NFBC338 under stressful conditions induced by drying, Appl. Environ. Microbiol. 72 (2006) 5104-5107.

[10] Corcoran B.M., Ross R.P., Fitzgerald G.F., Stanton C., Comparative survival of probiotic lactobacilli spray-dried in the presence of probiotic substances, J. Appl. Microbiol. 96 (2004) 1024-1039.

[11] Crowe J.H., Carpenter J.F., Crowe L.M., The role of vitrification in anhydrobiosis, Ann. Rev. Physiol. 60 (1998) 73-103.

[12] Crowe J.H., Crowe L.M., Carpenter J.F., Rudolph A.S., Aurell Winstrom C., Spargo B.J., Anchordoguy T., Interactions of sugars with membranes, Biochim. Biophys. Acta 947 (1988) 367-384.

[13] Crowe J.H., Crowe L.M., Jackson S.A., Preservation of structural and functional activity in lyophilised sarcoplasmin reticulum, 
Arch. Biochem. Biophys. 220 (1983) 477484.

[14] Crowe J.H., Hoekstra F.A., Crowe L.M., Membrane phase transitions are responsible for imbibitional damage in dry pollen, Proc. Natl. Acad. Sci. USA 86 (1989) 520-523.

[15] de Antoni G.L., Pérez P., Abraham A., Anón M.C., Trehalose, a cryoprotectant for Lactobacillus bulgaricus, Cryobiology 26 (1989) 149-153.

[16] Desmond C., Fitzgerald G.F., Stanton C., Ross R.P., Improved stress tolerance of GroESL-overproducing Lactococcus lactis and probiotic Lactobacillus paracasei NFBC 338, Appl. Environ. Microbiol. 70 (2004) 5929-5936.

[17] Desmond C., Stanton C., Fitzgerald G.F., Collins K., Ross R.P., Environmental adaptation of probiotic lactobacilli towards improvement of performance during spray drying, Int. Dairy J. 11 (2001) 801-808.

[18] Erkkila S., Suihko M.L., Eerola S., Petaja E., Mattila-Sandholm T., Dry sausage fermented by Lactobacillus rhamnosus strains, Int. J. Food Microbiol. 64 (2001) 205-210.

[19] Gardiner G.E., O’Sullivan E., Kelly J., Auty M.A., Fitzgerald G.F., Collins J.K., Ross R.P., Stanton C., Comparative survival rates of human-derived probiotic Lactobacillus paracasei and $L$. salivarius strains during heat treatment and spray drying, Appl. Environ. Microbiol. 66 (2000) 2605-2612.

[20] Gatlin L.A., Nail S.L., Protein purification and process engineering. Freeze drying: a practical overview, Bioprocess Technol. 18 (1994) 317-367.

[21] Green J.L., Angell C.A., Phase relations and vitrification in saccharide-water solutions and the trehalose anomaly, J. Phys. Chem. 93 (1989) 2880-2882.

[22] Greenspan L., Humidity fixed points of binary saturated aqueous solutions, J. Res. Nat. Bur. Stand. 81A (1977) 89-96.

[23] Hatley R.H., The effective use of differential scanning calorimetry in the optimization of freeze drying processes and formulations, Dev. Biol. Stand. 74 (1992) 105-119.

[24] Hoekstra F.A., Crowe L.M., Crowe J.H., Effect of sucrose on phase behaviour of membranes in intact pollen of Typha latifolia $L$., as measured with fourier transform infrared spectroscopy, Plant Physiol. 97 (1991) 1073-1079.

[25] Hubalek Z., Protectants used in the cryopreservation of microorgansisms, Cryobiology 46 (2003) 205-229.
[26] Jennings T.A., Lyophilisation - introduction and basic principles, CRC Press, Boca Raton, 1999.

[27] Koster K.L., Leopold A.C., Sugars and dessication tolerance in seeds, Plant Physiol. 88 (1988) 829-832.

[28] Labuza T.P., Kaanane A., Chen J.Y., Effect of temperature on the moisture isotherms and water activity shift of two dehydrated foods, J. Food Sci. 50 (1985) 385-391.

[29] Leslie S.B., Israeli E., Lighthart B., Crowe J.H., Crowe L.M., Trehalose and sucrose protect both membranes and proteins in intact bacteria during drying, Appl. Environ. Microbiol. 61 (1995) 3592-3597.

[30] Lievonen S.M., Laaksonen T.J., Roos Y.H., Glass transition and reaction rates: nonenzymatic browning in glassy and liquid systems, J. Agric. Food. Chem. 46 (1998) 2778-2784.

[31] Manley K.J., Fraenkel M.B., Mayall B.C., Power D.A., Probiotic treatment of vancomycin-resistant enterococci: a randomised controlled trial, Med. J. Aust. 186 (2007) 454-457.

[32] Marteau P.R., de Vrese M., Cellier C.J., Schrezenmeir J., Protection from gastrointestinal diseases with the use of probiotics, Am. J. Clin. Nutr. 73 (2001) 430S-436S.

[33] Oetjen G.W., Freeze-drying, Wiley-VCH, Weinheim, 1999.

[34] Paiva C.L., Panek A.D., Biotechnological applications of the disaccharide trehalose, Biotechnol. Annu. Rev. 2 (1996) 293-314.

[35] Patist A., Zoerb H., Preservation mechanisms of trehalose in food and biosystems, Colloids Surf. B 40 (2005) 107-113.

[36] Roos Y.H., Phase transition in foods, Academic Press Inc., San Diego, USA, 1995.

[37] Schoug Å., Olsson J., Carlfors J., Schnürer J., Håkansson J., Freeze-drying of Lactobacillus coryniformis Si3-effects of sucrose concentration, cell density, and freezing rate on cell survival and thermophysical properties, Cryobiology 53 (2006) 119-127.

[38] Sudoma A.L., Stabilisation of dried bacteria extended in particulate carriers, U. S. Patent No. 4956 295, 1990.

[39] Sun W.Q., Davidson P., Protein inactivation in amorphous sucrose and trehalose matrices: effects of phase separation and crystallization, Biochim. Biophys. Acta 1425 (1998) 235-244.

[40] Tunnacliffe A., Garcia de Castro A., Manzanera M., Anhydrobiotic engineering of bacterial and mammalian cells; is intracellular trehalose sufficient? Cryobiology 43 (2001) 124-132. 